ESTUDOS RBE?

\title{
A ampliação da base social da educação superior no contexto do Centro Universitário do Leste de Minas Gerais: o caso do ProUni
}

Edna Imaculada Inácio de Oliveira

Rosane Maria Kreusburg Molina

\section{Resumo}

Reúne resultados de pesquisa cujo foco foi o Programa Universidade para Todos (ProUni) no Centro Universitário do Leste de Minas Gerais (Unileste/MG). Objetivou identificar desafios e implicações do ProUni no contexto das práticas institucionais dessa Instituição de Educação Superior (IES) e a efetividade do Programa no que tange ao acesso de estudantes negros da Região Metropolitana do Vale do Aço (RMVA) ao ensino superior. Políticas afirmativas e a luta do Movimento Negro pela conquista do acesso ao ensino superior são os principais referenciais legais, políticos e históricos que sustentam a pesquisa. O ProUni foi investigado na perspectiva dos professores e gestores da IES por meio de análise documental e entrevistas. O Programa ampliou o ingresso de estudantes no universo acadêmico, mas ainda há ausência de ações para minimizar as narrativas do mito da democracia racial e efetivar a permanência dos bolsistas no ensino superior com sucesso. É legítimo, portanto, questionar que influências e agendas são reconhecidas nas ações do Estado ao implantar políticas afirmativas como o ProUni.

Palavras-chave: ProUni; políticas afirmativas; Movimento Negro; ensino superior. 


\section{Abstract \\ Expanding the social base of higher education in the context of UniLeste/MG: the case of ProUni}

This paper presents results of a research focusing on the Programa Universidade para Todos (ProUni) in the context of the Centro Universitário do Leste de Minas Gerais (UniLeste/MG). The purpose of the study was to identify challenges and implications of ProUni in the context of the institutional practices of UniLeste/MG, as well as the program's effectiveness in terms of black students' access to higher education in the Metropolitan Area of the Steel Valley. Affirmative action policies and the struggle of the Black Movement to achieve the access to higher education are the main legal, political and historical frameworks supporting the research. The ProUni was investigated from the UniLeste/MG professors' and managers' perspectives, by means of document analysis and interviews. The program has expanded the admission of students in the academic environment; however, there is still a lack of measures to minimize the narratives of the myth of racial democracy and to ensure that scholars complete higher education successfully. It is therefore legitimate to question what influences and agendas are recognized in the State's actions in implementing affirmative policies such as the ProUni.

Keywords: ProUni; affirmative action policies; Black Movement; higher education.

\section{Introdução}

Todo estudo que pretende identificar efeitos de políticas sociais impõe aos pesquisadores uma limitação básica: como delimitar as influências de uma política nos resultados avaliados? No caso das políticas educacionais, essa limitação apresenta-se de forma ainda mais complexa, pois os processos de ensinar e aprender em ambientes escolares estão circunscritos em dinâmicas institucionais que se constituem, por efeitos de macro e de micro políticas, de diferentes dimensões. Estas podem ser identificadas na composição demográfica, na estrutura, no tamanho, na organização curricular e social da instituição. Portanto, pesquisas que objetivam avaliar efeitos de políticas (Lee, 2010) obtêm melhores resultados quando trabalham com dados longitudinais, sem descuidar do rigor metodológico. Considerando essas recomendações, nossa pesquisa, por não trabalhar com dados longitudinais, caracteriza-se como um estudo de caso qualitativo 
exploratório sobre a efetividade do Programa Universidade para Todos (ProUni).

O objetivo geral do estudo foi compreender os desafios e as implicações produzidas pelo ProUni, como política afirmativa, no contexto das práticas institucionais do Centro Universitário do Leste de Minas Gerais (Unileste/MG). Mas, sobretudo: investigar, no locus do estudo, como a questão racial e a política afirmativa têm sido debatidas; identificar relações entre o ProUni e as demandas do Movimento Negro e de movimentos antirracistas quanto ao tema das políticas afirmativas para o acesso ao ensino superior; compreender as práticas institucionais desenvolvidas com a finalidade de garantir o sucesso e a permanência dos estudantes negros beneficiados pelo ProUni; dimensionar o quanto o ProUni potencializou o acesso de estudantes negros da Região Metropolitana do Vale do Aço (RMVA) ao ensino superior.

O ProUni, instituído pela Lei no 11.096/2005, oferece bolsas de estudo para acesso ao ensino superior em instituições privadas. Aderido pelo Unileste/MG, no mesmo ano, configurou-se como possibilidade de acesso ao ensino superior para jovens provenientes de escolas públicas e economicamente pobres, bem como para negros e professoras da rede pública da região. Vale lembrar que na região do Unileste/MG a universidade pública mais próxima está localizada a pelo menos duzentos quilômetros de distância. Como resultado, sobretudo no segundo semestre de 2005, observou-se um considerável número de estudantes aderindo ao ProUni e, com isso, docentes sentiram-se desafiados a pensar práticas diferenciadas em prol da permanência desses estudantes na universidade.

Neste estudo, nos ocupamos em investigar o caso dos estudantes afrodescendentes cujas reivindicações políticas pelo acesso e permanência adquiriu visibilidade nas últimas décadas do século 20, ocupando lugar de destaque na agenda governamental na atualidade.

O estudo por nós realizado estruturou-se no seguinte problema de pesquisa: quais os desafios e as implicações produzidas pela implantação do ProUni, no contexto das práticas institucionais do Unileste/MG, entre os anos de 2005 e 2007, objetivando a permanência, com qualidade, dos estudantes negros beneficiados pelo Programa?

Assumimos o desafio de pesquisar o ProUni e a política de ação afirmativa expressa em texto legal, bem como sua implantação no interior do Unileste/MG, visando compreender as condições de acesso, sucesso e permanência no ensino superior dos autodeclarados negros da RMVA, em Minas Gerais.

Consideramos a pesquisa ${ }^{1}$ como um desafio, porque as discussões acerca das políticas de acesso ao ensino superior, na maioria dos casos, estão relacionadas à política de cotas raciais. ${ }^{2} \mathrm{O}$ fato de um grupo racial ser beneficiado, segundo Bernardino (2004), faz com que preconceitos velados aflorem. Por isso, neste estudo, entendemos como pertinente recordar a trajetória de luta do Movimento Negro pelo acesso à educação nas décadas dos anos 1970, 1980 e 1990, antes de proceder à análise dos desafios e das implicações do ProUni no contexto da IES estudada. 
Sem esquecer que os dados gerados por esta pesquisa são insuficientes para qualquer tipo de generalização, acreditamos que sistematizar informações sobre os efeitos do ProUni na ampliação da base social da educação superior e as relações históricas do Movimento Negro com esta política, no contexto do Unileste/MG, pode colaborar para ampliar conhecimentos sobre o tema.

\section{O protagonismo negro: uma história de luta em busca de afirmação}

Uma das principais bandeiras do Movimento Negro tem sido a incorporação do tema da desigualdade racial como elemento central do debate, a partir da reivindicação de igualdade de direitos no acesso à educação. A demanda por cotas raciais e a conquista de leis, como a Lei no 10.639/2003, são grandes passos na busca por conteúdos e práticas educativas antirracistas. Vale a pena, por isso, identificar na história o quanto essas ações de resistência têm se constituído como estratégias promotoras dos processos educativos.

A atividade afro-brasileira expressava-se, nas primeiras décadas do século 20, sob a forma de entidades religiosas e associações recreativas. A Revolta da Chibata, liderada pelo marinheiro João Cândido, em 1910 na Baía da Guanabara/RJ, foi um marcante acontecimento para exigir o fim dos castigos corporais na Marinha do Brasil e o acesso à educação para os marinheiros (Munanga; Gomes, 2006).

Por outro lado, recordam-nos os mesmos autores, antes da década de 1920 já havia uma imprensa negra bastante ativa que, mais adiante, em setembro de 1931, deu origem à primeira organização nacional negro-brasileira: a Frente Negra Brasileira (FNB), que se tornou partido político e, em 1937, foi fechada pelo golpe que instalou o Estado Novo no Brasil. Um dos fundadores do FNB, dramaturgo, ator e ex-senador da República, Abdias do Nascimento, organizou, em 1944, o Teatro Experimental do Negro (TEN), no Rio de Janeiro, apostando no teatro como veículo de educação popular. O TEN organizou cursos de alfabetização (Nascimento; Nascimento, 2000), eventos, como a Convenção Nacional do Negro (1945-1946), a Conferência Nacional do Negro (19481949) e o $1^{\circ}$ Congresso do Negro Brasileiro (1950). Publicou o jornal O Quilombo, que defendia a ideia de que, enquanto não se universalizasse o acesso à educação pública no Brasil, seria necessário que estudantes negros a acessassem como bolsistas do Estado, antecipando, segundo Guimarães (2000), o que o Ministério da Educação (MEC) propõe hoje no bojo das políticas afirmativas.

Ao final da Convenção Nacional do Negro de 1945, uma assembleia votou e lançou um Manifesto à Nação Brasileira pela admissão de negros na educação secundária e superior e pela formulação de uma lei antidiscriminatória. Essa lei, publicada cinco anos depois, em 1951, com o nome de Lei Afonso Arinos, desenvolvida em conjunto com Gilberto Freire, foi a primeira lei nacional contra o racismo e o preconceito. 
Em 1964, a ditadura militar brasileira impôs a desarticulação dos movimentos sociais e, consequentemente, do Movimento Negro, que, a partir da década dos anos 1970, iniciou um novo processo de articulação com o objetivo de construir um conjunto de reivindicações, com destaque para a oportunidade de trabalho, renda e ascensão por meio da educação.

Iniciava-se, naquele momento, uma nova fase do Movimento Negro em busca da autoafirmação e do resgate da identidade étnico-cultural. Em 1974, foram realizadas as semanas afro-brasileiras organizadas pelo Centro de Estudos Afro-Asiáticos (RJ), a Sociedade de Estudos da Cultura Negra no Brasil (Salvador) e o Museu de Arte Moderna (RJ). Na mesma época, surge em Salvador a Sociedade Cultural Bloco Afro Ilê Aiyê e o Black Soul, que, naquele mesmo ano, marcaram o início da mudança nas expressões ostensivas da identidade negra na moda, na música e na dança (Telles, 2003). Em 1978, a transição política negra moderna completou-se com a unificação de várias organizações negras, fazendo nascer o Movimento Negro Unificado (MNU), que objetivava a organização de um movimento político, reivindicativo e de oposição, que não se prendesse somente à questão cultural. Dentre suas lutas prioritárias estava uma educação comprometida com os interesses do povo negro e de todos os oprimidos.

Em 1980, o professor Abdias do Nascimento publicou um texto de grande impacto na formação da consciência negra brasileira, intitulado "Quilombismo: um conceito científico emergente do processo histórico-cultural das massas afro-brasileiras". Nessa obra, o autor já sinalizava a necessidade da implantação de políticas afirmativas para o reconhecimento da cidadania da população negra. Ainda na década de 1980, surge o Programa Nacional do Centenário da Abolição, mais tarde transformado na Fundação Cultural Palmares. Segundo Telles (2003, p. 71), "contudo, para alguns analistas, a ênfase na cultura forneceu uma distração das necessidades socioeconômicas dos negros, como emprego, educação e saúde".

Vale lembrar que a Constituição nacional de 1988 representou avanço para a reflexão sobre a condição socioeconômica de homens e mulheres negras ao determinar, no art. $5^{\circ}$, que a prática de racismo é um crime inafiançável e imprescritível, sujeito à pena de reclusão.

Sem dúvida, no contexto das discussões sobre a necessidade de democratização do acesso ao ensino superior no Brasil, o Movimento Negro protagonizou o debate. E, como afirma Nascimento (2007), é o principal protagonista da luta pela ação afirmativa como prática social e como política de combate à desigualdade e de promoção da igualdade racial.

Na década de 1990, período marcado pela queda da ideia de "democracia racial", o Movimento Negro reformulou sua prática usando como eixo central a demanda por "políticas focalizadas", comprometidas com a população negra, com o objetivo de diminuir desigualdades entre brancos e negros. Em 1995, a celebração do tricentenário da imortalidade de Zumbi dos Palmares foi considerada um marco na luta e na 
busca de ações afirmativas pela promoção da igualdade racial (Marcha Zumbi contra o racismo, pela cidadania e a vida, 1996). Em resposta à Marcha, o então presidente da República, Fernando Henrique Cardoso, criou um Grupo de Trabalho Interministerial (GTI) com a missão de discutir e formular propostas e projetos políticos para a valorização e a melhoria das condições de vida da população afro-brasileira. Assim, a partir de 20 de novembro de 1995, consolidou-se o debate sobre ações afirmativas na agenda de políticas públicas do País. ${ }^{3}$

$\mathrm{Na}$ continuidade do processo de formulação, implantação e implementação de políticas inclusivas não discriminatórias, em 1996, o governo federal criou o Programa Nacional de Direitos Humanos (PNDH), que recomendava objetivos de curto, médio e longo prazo para mulheres, pessoas com deficiência física, povos indígenas e pessoas negras. A III Conferência Mundial contra o Racismo, Discriminação Racial e Intolerância Correlata, em Durban, na África do Sul, que teve a participação do Movimento Negro Brasileiro, foi um marco importante para a redefinição da agenda das relações raciais no mundo, em particular, no Brasil. O assunto ganhou relevância nos debates políticos do Brasil e ensejou a divulgação pública, principalmente por parte do Instituto de Pesquisa Econômica Aplicada (Ipea), de dados que não deixaram dúvidas sobre a gravidade da exclusão social da população negra na sociedade brasileira.

O relatório que o governo brasileiro levou à Conferência de Durban, em 2001, previa a adoção de cotas para estudantes negros no ensino superior, e esse fato, segundo Heringer (2006), contribuiu para que algumas universidades brasileiras passassem a discutir internamente propostas de ações afirmativas para estudantes negros. Outro exemplo da ampliação do debate foi a instituição da Lei no 10.639/2003, que incluiu no currículo oficial do ensino fundamental e médio de todo o País, alterando a LDB/96, a obrigatoriedade da temática "História e Cultura Afro-Brasileira". A Lei $n^{\circ}$ 10.678/2003 criou a Secretaria Especial de Políticas de Promoção da Igualdade Racial (Sepir), que, no campo do MEC, promoveu uma articulação na implantação da Lei no 10.639/2003 e na definição de programas de acesso de estudantes afrodescendentes ao ensino superior.

No início de 2004, como resultado das ações do Grupo de Trabalho Interministerial, o Ministério da Educação entregou à Casa Civil proposta de Medida Provisória que autorizava as universidades públicas a adotar cotas destinando $20 \%$ das vagas para estudantes que se autodeclarassem negros e com a pontuação mínima estipulada pelas universidades para legitimar o ingresso. Ainda no ano de 2004, o ministro da Educação, Tarso Genro, apresentou nova proposta para discussão: aproveitamento de cerca de 100.000 vagas ociosas nas universidades privadas por estudantes negros, indígenas, portadores de deficiência e ex-presidiários, naquele mesmo ano. A contrapartida do governo se materializava no plano de renúncia fiscal para as instituições que adotassem o sistema.

Assim, o ProUni foi instituído em 2004 por meio de Projeto de Lei, prevendo bolsas integrais de estudo em universidades privadas para
${ }^{3}$ Iniciativas desse período que merecem destaque: Pré-Vestibular para Negros e Carentes (PVNC), no Rio de Janeiro; Educação e Cidadania de Afrodescendentes e Carentes (Educafro), em São Paulo. 
jovens de baixa renda. Mesmo cercado de polêmicas, o governo decidiu editar a Medida Provisória do ProUni e, posteriormente, instituiu a Lei no 11.096/2005. O ProUni recebeu adesão de instituições privadas de ensino superior de todo o País e beneficiou, segundo o MEC, mais de 100.000 estudantes na sua primeira edição.

\section{Políticas afirmativas no ensino superior}

Sarmento (2008, p. 208) conceitua políticas de ação afirmativa da seguinte forma:

são medidas públicas ou privadas, de caráter coercitivo ou não, que visam promover a igualdade substancial por meio da discriminação positiva de pessoas integrantes de grupos que estejam em situação desfavorável e que sejam vítimas de discriminação e estigma social. Elas podem ter focos muito diversificados, como mulheres, os portadores de deficiência, os indígenas ou os afrodescendentes, e incidir nos mais variados campos, como educação superior, acesso a empregos privados ou cargos públicos, reforço à representação política ou preferências na celebração de contratos.

As ações afirmativas estão fundadas no princípio da equidade, enquanto as políticas de cotas, de preferência e de permanência são a operacionalização desse princípio.

Conforme Rosemberg (2006), no atual cenário brasileiro, as experiências de ação afirmativa em prol do acesso ao ensino superior de egressos do ensino médio público, negros e indígenas são de quatro tipos: aulas ou cursos preparatórios para acesso ao ensino superior e de reforço (melhoria do desempenho acadêmico); financiamento dos custos para acesso (inclusive no pagamento de taxas para o vestibular) e permanência no ensino superior; mudanças no sistema de ingresso nas instituições de ensino superior via metas, cotas, pontuação complementar, etc.; e criação de cursos específicos para esses segmentos raciais, tais como a licenciatura para professores indígenas da Universidade Federal de Roraima.

O fulcro normativo da ação afirmativa é o conceito de igualdade substantiva ou material daquilo que a democracia formal define como o que todos devem ter acesso: igualdade de todos perante a lei, igualdade substancial de oportunidade e tratamento. No caso brasileiro, a Constituição de 1988, art. 13, Inciso IV, garante a igualdade como direito de todos, sem preconceito de origem, raça, sexo, cor, idade e quaisquer outras formas de discriminação.

Outra questão muito debatida quando o assunto são as políticas afirmativas para o acesso ao ensino superior, mais especificamente a política de cotas, diz respeito ao mérito. Pode-se afirmar, entretanto, que a igualdade de oportunidades promovida pela ação afirmativa promove uma equalização das posições iniciais e, só a partir daí, o mérito é premiado. 
Concordando com o pressuposto de que a história é situada em contextos políticos, sociais e econômicos, a seguir, descrevemos e interpretamos a lei que institui o ProUni no contexto das propostas contidas em documentos como a Lei no 9.394/1996 (Lei de Diretrizes e Bases da Educação Nacional - LDB), e o Plano Nacional de Educação (PNE).

\section{As reformas do ensino superior na última década e a expansão do sistema}

Em 2003, em meio às expectativas de mudanças, foi anunciado o programa "Uma Escola do Tamanho do Brasil", coordenado pelo professor Newton Lima Neto. O documento apresentou um diagnóstico da educação superior e identificou a necessidade de expansão do sistema para atender a crescente demanda de vagas, prevendo a necessidade de dar perspectiva de ingresso no ensino superior privado a estudantes economicamente pobres em função da limitação de vagas no setor público (Costa, 2008). Entre as 27 propostas previstas nesse programa, uma serviu de base para a formulação de políticas para o acesso ao ensino superior com bolsa, como o caso do ProUni.

Uma análise do PNE e do ProUni, como medidas implementadas no contexto do projeto da reforma universitária, oferece um panorama de como essas ações refletem os embates que cercam o tema.

O ano de 2001 marcou o começo das ações afirmativas iniciadas pelo governo federal em diferentes âmbitos. Em janeiro daquele ano, foi aprovado o PNE, elaborado para o decênio 2001-2011, com os seguintes objetivos: elevação do nível de escolaridade da população; melhoria da qualidade do ensino em todos os níveis; redução das desigualdades sociais e regionais no tocante ao acesso e à permanência na educação pública; democratização da gestão do ensino público, obedecendo aos princípios da participação dos profissionais da educação na elaboração do projeto pedagógico da escola e da participação das comunidades escolares e locais em conselhos escolares ou equivalentes. Entre outras prioridades, garantia a ampliação do atendimento na educação infantil, no ensino médio e na educação superior. No que tange ao ensino superior, o PNE indicou percentuais a serem alcançados:

4 Educação superior

[...]

4.3 Objetivos e metas

1) Prover, até o final da década, a oferta de educação superior para, pelo menos, 30\% da faixa etária de 18 a 24 anos;

2) ampliar a oferta de ensino público de modo a assegurar uma proporção nunca inferior a $40 \%$ do total das vagas, prevendo inclusive a parceria da União com os Estados na criação de novos estabelecimentos de educação superior (vetado);

[...]

19) criar políticas que facilitem às minorias, vítimas de discriminação, o acesso à educação superior, através de programas de compensação 
de deficiências de sua formação escolar anterior, permitindo-lhes, desta forma, competir em igualdade de condições nos processos de seleção e admissão a esse nível de ensino (Brasil. Lei nº 10.172, 2001).

Em 2007, o governo lançou o Plano de Desenvolvimento da Educação (PDE), com prazo de cumprimento dos objetivos até 2022; desconsiderando os planos de metas anunciados no PNE, o PDE estabeleceu novas metas à educação superior: Programa Universidade Aberta (UAB); Programa de Apoio a Planos de Reestruturação e Expansão das Universidades Federais (Reuni); Fundo de Financiamento Estudantil (Fies); Programa Universidade para Todos, com parcelamento de débitos fiscais e previdenciários (Refis) às instituições de ensino superior em contrapartida à oferta de mais vagas entre outras metas. Saviani (2007), ao comparar o PNE com o PDE, afirma que o segundo não se define como estratégia para o cumprimento das metas estabelecidas no PNE, pois o PDE se compõe de ações que não se articulam com o primeiro.

Sobre a reforma da educação superior, o governo Lula iniciou oficialmente seu curso com o Decreto de 20 de outubro de 2003, que instituiu o GTI encarregado de analisar a situação da educação superior brasileira e apresentar um plano de reestruturação, desenvolvimento e democratização das instituições federais de ensino superior. Em 2004, foi apresentada a primeira versão do plano e, em abril de 2006, a terceira e última versão (Projeto de Lei $\left.n^{\circ} 7.200 / 2006\right)$, ambas pensadas com base no PNE, que determinava que, ao final do período de dez anos, fossem ofertadas matrículas em cursos superiores correspondentes a 30\% da população de jovens entre 18 e 24 anos.

O relatório final do GTI foi divulgado, extra oficialmente, em dezembro de 2003. O texto inicia-se reconhecendo a situação de crise da educação superior brasileira, em especial das universidades federais, e atribui o problema à crise fiscal do Estado. Também demonstra que a crise atinge igualmente as instituições privadas, ameaçadas pelo risco da inadimplência generalizada e por uma crescente desconfiança em relação a seus diplomas. Após esse preâmbulo, o relatório apresenta a seguinte solução: um programa emergencial de apoio ao ensino superior, especialmente às universidades federais (Brasil. Presidência..., GTI, 2003). Para Sguissardi e Silva Jr. (2005), a crise estava vinculada ao processo que atravessou o governo anterior, de modelo fortemente neoliberal, momento em que a educação foi incluída no setor de atividades não exclusivas do Estado.

Em dezembro de 2004, o governo federal, por meio do Ministério da Educação, divulgou o Anteprojeto de Lei da Educação Superior, contendo algumas das principais diretrizes da reformulação desse nível de ensino. Os fundamentos, afirma Otranto (2006), estavam calcados em marcos regulatórios defendidos por organismos internacionais. Entre essas medidas, podem-se destacar:

a) o Sistema Nacional de Avaliação Superior (Sinaes); 
b) o Decreto $\mathrm{n}^{\circ} 5.205 / 04$, que regulamenta parcerias entre as universidades federais e as fundações de apoio, viabilizando a captação de recursos privados para financiar suas atividades;

c) a Lei $n^{\circ}$ 10.973/04, de Inovação Tecnológica, vinculada ao Ministério de Ciência e Tecnologia;

d) o Projeto de Lei $n^{\circ} 3.627 / 2004$, que institui o sistema especial de reserva de vagas;

e) os Projetos de Lei e Decretos que tratam da reformulação da educação profissional e tecnológica;

f) a medida provisória $\mathrm{n}^{0} 208$, de 20 de agosto de 2004, que institui a Gratificação de Estímulo à Docência (GED);

g) o Projeto de Parceria Público-Privada, Lei no 11.079, de 30 de dezembro de 2004, que institui normas gerais para licitação e contratação de parceria público-privada (PPP) no âmbito da administração pública;

h) o ProUni (Lei n 11.096/2005), que trata da ampliação de isenção fiscal para as instituições privadas de ensino superior em troca de vagas.

\section{O Programa Universidade para Todos (ProUni)}

O ProUni, concordando com afirmações de Marinho (2005), serviu de carro-chefe da propaganda do governo na democratização da educação superior brasileira. No primeiro processo seletivo, o ProUni disponibilizou 112 mil bolsas em 1.142 instituições de ensino superior em todo País para estudantes com boas notas no Exame Nacional do Ensino Médio (Enem). De acordo com o MEC, a implementação do ProUni, somada à criação de dez universidades federais e 49 novos campi, ampliou significativamente o número de vagas na educação superior, interiorizou a educação pública e gratuita e minimizou as desigualdades regionais.

O Programa insere-se nas discussões que envolvem a Reforma Universitária, que, além do ProUni, segundo Catani, Hei e Giglioli (2006), conta com outras medidas, como a ampliação das universidades federais e a instituição de cotas para estudantes egressos da rede pública (subcotas para negros e indígenas) em instituições federais de ensino superior. Dessa forma, o ProUni é visto como um programa de cunho social, que visa diminuir as desigualdades de acesso ao ensino superior no Brasil, sendo, ao mesmo tempo, extremamente questionado por ser considerado como uma ação do governo que, em última análise, beneficia as instituições de ensino superior privadas. As bolsas de estudos integrais e parciais para estudantes são concedidas em troca da renúncia fiscal.

As instituições de ensino que aderem ao ProUni ficam isentas de uma série de impostos, dentre eles: imposto de renda da pessoa jurídica; contribuição social sobre o lucro líquido; contribuição social para financiamento da seguridade social; e contribuição para o programa de integração social. Faceira (2006) relembra que os mecanismos de renúncia fiscal já foram 
utilizados anteriormente no Brasil nas décadas dos anos 1960 e 1970, como forma de incentivo à expansão de vagas, tornando-se um ponto central no financiamento do ensino superior privado brasileiro. Segundo a autora, até 1996 praticamente todos os estabelecimentos particulares de ensino usufruíram de imunidade tributária sobre a renda, os serviços e o patrimônio. Citando o art. 20 da atual LDB, a autora relembra que houve, formalmente, a promoção de diferenciação institucional intrassegmento privado e, a partir daí, as instituições passaram a ser classificadas em privadas lucrativas e sem fins lucrativos (confessionais comunitárias e filantrópicas). As IES lucrativas deixaram de se beneficiar diretamente de recursos públicos, enquanto as sem fins lucrativos permaneceram imunes ou isentas à incidência tributária. A mudança legislativa permitiu ampliar a arrecadação da União e dos municípios e aumentou os custos operacionais dos estabelecimentos de ensino.

Ao reportar-se à década dos anos 1990, Faceira (2006) assinala que, com o baixo crescimento econômico do País, o aumento do número de desemprego e a queda na renda real, as IES de ensino privado começaram a conviver com problemas de inadimplência em função dos limites estruturais do poder aquisitivo da população. Ao mesmo tempo, a partir daquela década foram intensificados os debates no Brasil sobre a democratização do acesso ao ensino superior, destacando a política de cotas nas universidades públicas.

É nesse contexto que surge o ProUni, como oportunidade de as instituições privadas enfrentarem as ameaças pelo peso das vagas ociosas aliado ao discurso de inclusão social. Elementos contextuais justificam a consideração de que a implantação do ProUni também sofreu pressão imprimida por associações representativas do segmento privado. Esse movimento fez com que a evolução do texto legal fosse em direção ao afrouxamento do aparato estatal, tendo como empecilho a escassez de vagas públicas e gratuitas, o que estimulou a expansão das instituições de ensino superior privadas, tornando visível, como afirma Carvalho (2006), sua articulação com a política fiscal.

Nesse sentido, é prudente ampliar a compreensão do ProUni, analisando a trajetória de sua implantação até a aprovação da lei que o sancionou, bem como avaliar as condições da política afirmativa incluída no Programa por meio da oferta de bolsas aos autodeclarados negros e indígenas como política pública respaldada pela sociedade civil, principalmente no que diz respeito à luta do Movimento Negro pela conquista do diploma de graduação para estudantes negros.

\section{A trajetória da Lei $\mathbf{n}^{\circ}$ 11.096/05}

Primeiramente, o MEC pretendia instituir o ProUni por meio de Medida Provisória. No entanto, a decisão do governo foi encaminhar Projeto de Lei (PL) ao Congresso em maio de 2004. Inicialmente, foi assim descrito: 
Art. $1^{\circ}[\ldots]$

$\S 1^{\circ}$ A bolsa de estudo integral será concedida a brasileiros não portadores de diploma de curso superior, cuja renda familiar per capita não exceda o valor de até um salário mínimo e meio.

$\S 2^{\circ}$ A bolsa de estudo parcial de cinquenta por cento será concedida a brasileiros não portadores de diploma de curso superior, cuja renda familiar per capita não exceda o valor de até três salários mínimos. (Brasil. Medida Provisória no 213, 2004).

As bolsas atenderiam a cerca de 80 mil estudantes, sendo destinadas apenas aos concluintes do ensino médio em escolas públicas e à formação de professores da rede pública em cursos de licenciatura ou pedagogia. Os critérios para selecionar beneficiários foram dois: a nota e o perfil socioeconômico do estudante no Enem, com exceção para professores da rede pública. Ingressantes em nível superior por meio do ProUni estavam dispensados do processo seletivo específico das instituições privadas. O Programa destacou-se por incluir políticas afirmativas, por meio da oferta de bolsas aos autodeclarados negros e indígenas.

No entanto, desde o anúncio de que o Projeto de Lei seria encaminhado ao Parlamento, em maio de 2004, até a versão definitiva da Lei n ${ }^{\circ} 11.096 / 05$, em janeiro de 2005, o Programa sofreu diversas alterações, influenciadas pelas IES particulares e beneficentes. A concessão de bolsas de estudo integrais e parciais para estudantes de ensino superior em troca de renúncia fiscal, afirma Carvalho (2006), surge acompanhada pela retórica de justiça social e de inclusão das camadas sociais menos favorecidas, cujo principal indicador é o baixo contingente de estudantes de 18 a 24 anos que frequentam o ensino superior. O evidente respaldo da sociedade civil em busca do diploma de graduação encontra, dessa forma, eco na pressão das associações representativas de segmento privado. Acrescentamos aqui uma observação feita por Catani, Hei e Giglioli (2006), de que o princípio do ProUni segue essa orientação: promove o acesso à educação superior com baixo custo para o Estado, isto é, materializa uma engenharia administrativa que equilibra impacto popular, atendimento às demandas do setor privado e regulagem das contas do Estado, cumprindo a meta do PNE - prover, até o final do decênio 2001-2011, a oferta de educação superior para, pelo menos, 30\% da população na faixa etária entre 18 e 24 anos. Para o cumprimento dessa meta, conta com a alta ociosidade de vagas no ensino superior privado, que atingiu 35\% das vagas em 2002, 42\% em 2003 e 49\% em 2004.

No Projeto de Lei referente ao ProUni, o vínculo das IES valeria por dez anos, renovável por igual período. Não poderiam participar instituições com desempenho insuficiente no Sinaes por dois anos consecutivos ou três intercalados, no período de cinco anos. Período abrandado, no texto da Lei no 11.096/2005, para desempenho insuficiente no Sinaes por três anos seguidos.

Enquanto o Projeto de Lei condicionava a participação das IES no financiamento ao estudante do ensino superior (Fies) à adesão ao ProUni, na medida provisória, essa restrição foi suavizada: o acesso ao Fies passou a ser prioritário para as IES aderentes ao ProUni (Brasil, 2004). 
Quando o Projeto de Lei chegou ao Congresso, as mantenedoras propuseram modificações no texto que regulamenta o ProUni. O Projeto de Lei recebeu 292 propostas de emenda ao longo da trajetória de tramitação no Congresso. Há registros (Constantino, 2004) de que a maioria delas beneficiava as mantenedoras. A Medida Provisória n 213 do ProUni, editada em 13 de janeiro de 2004, adotou quase todas as propostas das IES privadas (Catani; Hey; Giglioli, 2006).

A Lei $n^{\circ}$ 11.096, de 13 de janeiro de 2005, foi sancionada pelo Presidente Lula. $\mathrm{O}$ art. $1^{\circ}$ menciona:

Fica instituído, sob a gestão do Ministério da Educação, o Programa Universidade para Todos - ProUni, destinado à concessão de bolsas de estudo integrais e bolsas de estudo parciais de $50 \%$ ou de $25 \%$ para estudantes de cursos de graduação e sequenciais de formação específica, em instituições privadas de ensino superior, com ou sem fins lucrativos.

Em junho de 2005, o governo anunciou um "pacote" para a área educacional, que incluía a criação, por meio da Medida Provisória, da bolsa-permanência do ProUni no valor de R\$ 300,00 (trezentos reais) mensais, oferecida em número variável, a cada semestre, e distribuída segundo critérios de renda familiar per capita, entre outros. A Lei no 11.180/2005 instituiu a bolsa-permanência para bolsistas integrais do ProUni, que foi regulamentada pela Portaria n 569/2006, do Ministério da Educação:

Art. $1^{\circ}[\ldots]$

$\S 1^{\circ}$ A bolsa-permanência será concedida a estudantes matriculados em cursos de Agronomia, Ciência da Computação, Enfermagem, Engenharias, Farmácia, Fisioterapia, Informática, Medicina, Odontologia e Veterinária, com no mínimo 6 (seis) semestres de duração e cuja carga horária média seja superior ou igual a 6 (seis) horas diárias de aula.

Carvalho (2006) ressalta que é importante contextualizar o ProUni em ambiente econômico mais amplo e em mudanças ocorridas na forma de operação da política fiscal, que alteraram os espaços de financiamento das políticas públicas. É nesse macroambiente econômico que se compreende porque a renúncia fiscal torna-se novamente relevante como mecanismo de financiamento da política pública para a educação superior privada no Brasil. As críticas recebidas pelo ProUni foram ao encontro dos questionamentos de muitos pesquisadores. Souza (2004), por exemplo, argumenta que o aspecto mais grave é que o Programa não prevê mecanismos de controle sobre a qualidade dos cursos. A crítica apresentada por Heringer (2007) refere-se a um suposto mecanismo de exclusão: ao propor reservar vagas nas universidades privadas para negros, indígenas e estudantes de baixa renda, o MEC estaria justamente mantendo a segmentação que já existe.

A questão da não definição das condições de acesso às vagas pelos estudantes de baixa renda nas universidades públicas federais perpetua um problema histórico, envolvendo a diluição das fronteiras entre público e privado. Sguissardi e Silva Junior (2005) expressam bem 
essa complexidade, ao ressaltarem que o ProUni é decorrente do atual paradigma político de oferta, com base em rubricas do orçamento da União, denominado pelos cientistas políticos de políticas focais, em contraposição às políticas universais.

Com relação ao financiamento, Carvalho (2006) elabora uma crítica sobre a concessão de bolsas de estudos integrais e parciais para estudantes de ensino superior em troca de renúncia fiscal. Segundo a autora, essa concessão surge acompanhada pela retórica de justiça social e pelo argumento de exclusão das camadas sociais economicamente pobres, cujo principal indicador é o baixo contingente de estudantes de 18 a 24 anos nesse nível de ensino.

Para Catani, Hey e Giglioli (2006), ao invés de privilegiar as IES privadas, o governo poderia investir no setor público como estratégia para democratizar o ensino superior. Já segundo Mancebo (2004), o MEC optou por conceder benefícios e não promover direitos; afirma também que até como "política assistencialista" o ProUni é fraco, porque espera que as IES privadas "cuidem" da permanência dos estudantes.

Apesar de todas as críticas e polêmicas, o ProUni destacou-se como política afirmativa por destinar percentual de bolsas de estudo a negros e indígenas. Escott (2005, p. 41), por exemplo, diz: "A Medida Provisória $n^{0} 213 / 04$ parece ser o primeiro passo para reparação das perdas historicamente acumuladas pelos grupos em desigualdade social".

É digno de destaque, também, o posicionamento da Associação Nacional dos Dirigentes das Instituições Federais de Ensino Superior (Andifes) em relação ao ProUni, cuja divulgação, em 2004, se deu em documento denominado "Manifesto sobre a criação de vagas públicas nas universidades particulares, o Programa Universidade para Todos". Posicionamento semelhante ao da Andifes é o assumido por Rosemberg (2006), reconhecendo que o ProUni favorece a possibilidade de um maior contingente de jovens ingressarem nas universidades, sem deixar de lembrar que a perspectiva da ação afirmativa na educação não é apenas essa ampliação, mas a implementação de ações complementares para assegurar a permanência e o sucesso nesse nível de formação, como revisão dos projetos políticos pedagógicos e a ampliação de recursos materiais e humanos. Esse, aliás, foi o foco do nosso estudo: compreender, no caso do Unileste/MG, se o ProUni representa um passo concreto em direção à conquista de um direito democrático.

\section{O caso do Unileste/MG}

O Unileste/MG localiza-se na Região Metropolitana do Vale do Aço (RMVA) - composta pelos municípios de Ipatinga, Timóteo, Coronel Fabriciano e Santana do Paraíso -, aglomerado urbano de aproximadamente 532 mil habitantes, segundo dados de 2010 do IBGE.

No entorno da RMVA estão 22 cidades que integram o Colar Metropolitano: Açucena, Antonio Dias, Belo Oriente, Braúnas, Bugre, 
Córrego Novo, Dom Cavati, Dionísio, Entre Folhas, Iapu, Ipaba, Jaguaraçu, Joanésia, Marliéria, Mesquita, Naque, Periquito, Pingo d’Água, São José do Goiabal, São João do Oriente, Sobrália e Vargem Alegre. A região tornou-se conhecida internacionalmente por suas grandes empresas, como a Cenibra, a Acesita e a Usiminas, todas exportadoras.

Deu-se, no princípio do século 20, o início efetivo do desenvolvimento da região, que se acentuou com a construção da ferrovia Vitória-Minas, inaugurada em 1922. Na esteira do ciclo industrial da Era Vargas, desenhado principalmente para a implantação da indústria de base, conjugada à vocação natural do Estado, a criação da Acesita, na década dos anos 1940, trouxe para a região um grande número de trabalhadores.

Em 1956, cresceram movimentos pela concretização da futura Usiminas, construída a partir de 1958 e inaugurada em 1962. Nos anos 1960, houve novo surto populacional com a instalação da Usiminas em Ipatinga. Na década dos anos 1970, a Cenibra foi fundada no município de Belo Oriente, entrando em operação em 1977. Com a implantação dessas três grandes empresas, houve aumento significativo e sistemático da população regional, situação que também viabilizou o desenvolvimento de outros setores da economia.

Nos mandatos presidenciais de Collor de Mello (1990-1991), seguido por Itamar Franco (1992-1994) e acentuando-se com Fernando Henrique Cardoso (1995-2002), efetivaram-se reformas orientadas para o mercado, além da reconfiguração das esferas pública e privada no âmbito do Estado e no ensino superior. Sguissardi (2006) acentua a busca do equilíbrio orçamentário como regra, mediante cortes nos gastos com os serviços públicos e, em especial, com a aprovação da Lei da Responsabilidade Fiscal, a privatização das empresas estatais e de serviços públicos. De dezenas de empresas estatais, restaram apenas algumas de grande expressão, como a Petrobrás, o Banco do Brasil e a Caixa Econômica Federal. Esse processo atingiu fortemente as empresas da RMVA - todas foram privatizadas, o que gerou grande índice de desemprego.

A história do Unileste/MG (Benedito Junior, 2000) tem origem na década dos anos 1960, quando o padre José Maria de Man, nascido na Holanda, veio como missionário para a América Latina. O missionário fundou, em junho de 1965, o Movimento Operário Cristão, instituição que deu origem ao planejamento das obras do Colégio Técnico de Coronel Fabriciano e, posteriormente, da Universidade do Trabalho. Em 1967, iniciaram-se as atividades letivas do Colégio Técnico de Coronel Fabriciano. Em 1968, foram iniciados os cursos de Letras e Estudos Sociais e, no ano seguinte, a faculdade de Filosofia. Depois de fundar e colocar em funcionamento o Colégio Técnico, e já com vista à Faculdade de Filosofia e Estudos sociais, foi criada a Fundação Populorum Progressio.

Em decorrência do regime vigente no País na época, e pelo fato de estar em zona metalúrgica, a região foi considerada área de segurança nacional, já que reunia muitos operários e, portanto, guardava a possibilidade de movimentos grevistas, além disso, o padre José Maria de Man teve dificuldades políticas em seu trabalho, por defender concepções incompatíveis com a "ordem" de uma área de segurança nacional. 
Em 1976, o mesmo padre doou a Sociedade Educacional União e Técnica (Seut) à Sociedade Mineira de Cultura (SMC), mantenedora da Universidade Católica de Minas Gerais (UCMG). A razão foi o desejo de levar a UCMG para a região.

Em 1984, a Sociedade Mineira de Cultura propôs mudança do nome da UCMG para Pontifícia Universidade Católica de Minas Gerais (PUC/MG), campus de Coronel Fabriciano.

Em 1997, iniciou-se o debate em torno da criação do Unileste/MG, concluído em 1998 e que provocou reestruturação acadêmica completa para adequar-se à Lei no 9.394/96. Em junho de 2000, foi assinada a portaria que transformou o Instituto Católico de Minas Gerais (ICMG) em Centro Universitário, esse foi um ano marco na instituição pelo fato de registrar um aumento significativo no número de estudantes mediante criação de novos cursos universitários para manter a demanda regional de ensino e atrair estudantes de outras regiões. Entretanto, a partir desse ano também houve a implantação de várias outras instituições privadas na região, em decorrência de uma diversidade institucional no Brasil.

Em junho de 2005, o ICMG, mantenedor do Unileste/MG, passou a integrar a União Brasiliense de Educação e Cultura (Ubec) juntamente com as outras cinco congregações religiosas, conservando o nome Unileste/MG.

Com o aumento do número de instituições privadas e com a criação de uma legislação favorável a elas, a RMVA foi lugar da implementação de várias instituições de ensino superior. ${ }^{4}$

Com a implantação do ProUni, a partir de 2005, houve aumento significativo do número de estudantes no Unileste/MG: em 2007, eram 1.178 bolsistas, em um universo de 6.597 estudantes matriculados. O critério de disponibilidade de vagas para o Programa na instituição é calculado em função do número de estudantes matriculados pagantes, conforme Lei $\mathrm{n}^{\circ}$ 11.096/2005. Assim, cursos com maior número de estudantes possuem maior número de bolsistas, proporcionalmente.

Atualmente, o Unileste/MG possui três campi: Coronel Fabriciano, Timóteo e Ipatinga. Seus 27 cursos de graduação atendem estudantes de toda a RMVA, carente de instituições de educação superior públicas. A maioria dos jovens é de família de trabalhadores do comércio e da indústria. Os que possuem melhores condições socioeconômicas migram para a capital, Belo Horizonte, a cerca de 200 quilômetros. Os que ingressam no Unileste/MG são, em sua maioria, da própria região, oriundos de escolas públicas e trabalham para custear seus estudos.

\section{Aspectos metodológicos observados no estudo}

Guiados pela convicção de que quando há estreita relação entre a indagação epistemológica e o contexto empírico (Stake, 1999) o estudo de caso é uma opção teórico-metodológica recomendada, optamos por este desenho. A revisão bibliográfica, por um lado, permitiu-nos compreender as políticas afirmativas direcionadas ao acesso ao ensino superior,
${ }^{4}$ Univaço (1998), composta pelas faculdades de Medicina, Direito e Fisioterapia; Unipac (2000); Faculdade Pereira Freitas (2002); Faculdade Pitágoras (2004); Fatemg (2004); Fati (2004); Inedi (2005). 
implementadas como políticas de cotas (Rodrigues, 2005; Oliveira, 2006; Silva, 2007); por outro, que as políticas públicas de acesso ao ensino superior (PNE; PDE) e a trajetória do ProUni, da Medida Provisória à Lei (Catani, Hey, Giglioli, 2006; Mancebo, 2004; Carvalho, 2006; Constantino, 2004; Sguissardi, 2006).

No decorrer do processo analítico (Triviños, 2001), compreendemos as políticas afirmativas como bandeira de luta dos movimentos sociais protagonizados pelo Movimento Negro em prol do acesso ao ensino superior, além da polêmica da adoção dessas políticas (Bernardino, 2004; Munanga, 2006; Escott, 2005; Guimarães, 2000; Henriger, 2006; Rosemberg, 2006; Carvalho, 2006; Nascimento, 2000; Silvério, 2004; Telles, 2003; Oliveira, 2004).

A coleta dos dados deu-se por meio de três instrumentos: análise de documentos, entrevista semiestruturada e diário de campo, utilizados conforme orientações de Bogdan e Biklen (1994), Ludke e André (1986), Triviños (2001), entre outros.

A investigação foi focalizada na área de Ciências da Educação, curso de Pedagogia. Essa escolha deu-se pelo fato de que o art. $2^{\circ}$, inciso III, da Lei n 11.096/05 refere que a destinação das bolsas é prioritariamente para estudantes do curso de Pedagogia, para formação do magistério da formação básica, independentemente da renda a que se referem os §§ $1^{\circ}$ e $2^{\circ}$ do art. $1^{\circ}$ dessa lei.

Esse aspecto legal gerou um aumento no número de estudantes matriculados nesses cursos. Somando, no momento da coleta, estudantes matriculados nos cursos de Pedagogia e Normal Superior, o percentual de bolsistas foi maior do que nos demais cursos, totalizando $37,74 \%$ da matrícula. Do universo de estudantes matriculados na graduação, 13,51\% são bolsistas do ProUni. O curso que detém o maior número de bolsas é o de Pedagogia: dos 262 estudantes matriculados, 30,34\% são bolsistas do Programa. Causa estranheza também o fato de muitos alunos, no preenchimento do formulário de candidatura à vaga e de matrícula, não se declararem negros e, com isso, possíveis cotistas. Antes da adesão do Unileste/MG ao ProUni tanto a área de Ciências da Educação quanto o curso de Pedagogia concentravam o menor número de matrícula, situação imediatamente revertida com a Lei no 11.096/05.

Os critérios de representatividade para compor o grupo de colaboradores basearam-se nos setores de trabalho dos entrevistados e no tempo na instituição. Os atores que colaboram com este estudo são professores dos cursos de Pedagogia e História, têm vínculo com o Núcleo de Estudos Afro-Brasileiro (Neab) e integram a equipe de coordenação do Programa de Assessoria Pedagógica Institucional (Proapi). A descrição do grupo de atores ${ }^{5}$ pode ser sintetizada da seguinte forma: a professora

${ }^{5}$ Os atores colaboradores assinaram termo de consentimento concordando com a divulgação dos resultados do estudo em periódicos científicos. Seus nomes foram alterados com o intuito de preservar suas identidades. Milena está na instituição há quinze anos e compõe, juntamente com o professor Paulo, o Neab; a professora Alice está na instituição há oito anos e há quatro coordena as atividades relacionadas à capacitação de professores, além de acompanhar a elaboração e execução de projetos pedagógicos e institucionais; a secretária Tatiana, há sete anos, coordena e 
orienta todo o processo de implementação de bolsas do Fies e, desde 2005, orienta também o processo de implementação do ProUni; a professora Guta, por sua vez, está na instituição há sete anos, e, há cinco, orienta e coordena as ações realizadas no projeto de Leitura e Produção de Textos, considerado como política para a melhoria do desempenho e permanência dos estudantes; a professora Maria Eduarda está na instituição há vinte anos, sendo atualmente a coordenadora do curso de Pedagogia.

\section{Resultados}

Os dados gerados pela pesquisa são insuficientes para qualquer tipo de generalização, no entanto, evidenciam resultados que colaboram para ampliar conhecimentos sobre o tema. As evidências coletadas na análise de textos legais, entre outros, mostram que o ProUni foi instituído diante da demanda da sociedade por acesso ao ensino superior público de qualidade e, no âmbito do projeto de Reforma Universitária, como uma das medidas para sua implementação.

O contato com os colaboradores da instituição mostrou que o processo de discussão das práticas desenvolvidas desde a implantação do ProUni foi singular, possibilitando a inserção de um perfil diferenciado de estudantes, embora alguns professores afirmem não perceber essa inserção. Os números permitem afirmar que o ProUni, no caso do Unileste/MG, está constituindo-se como possibilidade antes inexistente de ingresso em cursos superiores para estudantes de baixa renda; representa oportunidade para professores da rede pública, que há muito não estudavam, bem como para negros da região. No entanto, o acesso à educação superior para a população brasileira de 18 a 24 anos é meta a ser alcançada, e a permanência e o êxito se constituem desafios de grande complexidade.

Nessa IES, o ProUni produziu ações isoladas nas práticas institucionais e de docentes (negros ou não) sensibilizados com o trato da questão racial.

Nos projetos pedagógicos analisados, não há ênfase para o ProUni entre as bolsas, apenas o projeto pedagógico do curso de Letras faz breve citação ao Programa. Nos demais documentos que têm como objetivo a divulgação da instituição, a adesão da IES ao ProUni aparece como diferencial, como ferramenta de marketing, juntamente com o ambiente virtual e os laboratórios.

Quanto ao perfil dos estudantes bolsistas, os depoimentos dos professores mostram que não se evidencia o quesito cor/raça, bem como não é possível identificar quem são esses estudantes, a não ser em situações em que o próprio bolsista se manifesta. Os impactos da entrada no ensino superior de um perfil diferenciado de estudantes, permitida pelo ProUni, também não são percebidos por todos.

É possível perceber, na fala dos entrevistados e na análise dos documentos, que a concepção de qualidade do ensino superior é multidimensional: há concepções com base saudosista, utilizando parâmetros do passado, e há concepções que se apoiam em uma perspectiva liberal 
(Castanho, 1989), ou neoliberal, em que o ensino teria como objetivo preparar pessoas qualificadas para o mercado de trabalho. O conceito de qualidade de ensino como crítico-dialético também é evidenciado. A chave dessa perspectiva é a ideia de que o estudante poderia desenvolver, por meio do ensino e da pesquisa, competência formal técnica aliada à competência política. Nessa concepção, a escola é vista como espaço de lutas políticas, contradições sociais, relações de poder e conflito (Fernandes, 2002).

A implantação da Lei no 10.639/2003 foi um grande avanço, ao cobrar mudanças na prática e no currículo. Em relação às iniciativas no campo da formação de professores para a diversidade étnico-racial, essa discussão era tratada de forma isolada antes da referida lei. Posteriormente a ela, houve maior sensibilização, o que provocou sua inclusão como disciplina no currículo do curso da área de formação de professores, mesmo que de forma polêmica.

A questão racial no ambiente acadêmico da Unileste/MG, entretanto, não é tratada de forma específica, diluindo-se em palavras e expressões no projeto institucional e pedagógico do curso de Pedagogia, como "respeito às diversidades", "pluralidade cultural", "diferenças sociais".

É possível afirmar que o trato da questão racial, enfatizado a partir dos debates sobre as políticas afirmativas em prol do acesso ao ensino superior, desencadeou mobilização para as práticas institucionais diferenciadas. No entanto, como ressalta Queiroz (2002), a ausência de informações sobre as condições raciais dos estudantes que frequentam os cursos tem, por vezes, dificultado a análise da situação dos segmentos raciais nas IES, e o caso do Unileste/MG não é diferente.

Embora as políticas afirmativas na modalidade de cotas já tenham sido implementadas por muitas instituições de educação pública e por iniciativas de outros setores, ainda não há concordância com relação a sua adoção. No Unileste/MG, as opiniões dos colaboradores também divergem.

Um ganho importante da implementação dessas políticas pode ser entendido como a possibilidade do debate e o reconhecimento do Movimento Negro como novo personagem na cena brasileira, passando a exigir do Estado e das escolas públicas e particulares práticas que visam o reconhecimento da diversidade racial, embora nem sempre considerado.

Sobre os efeitos do ProUni ou das políticas afirmativas no Unileste/ MG, há evidências de que favoreceram o ingresso de estudantes com perfil diferenciado daqueles até então matriculados, beneficiando o atendimento a uma demanda reprimida, o que foi evidenciado nos depoimentos dos colaboradores. No entanto, a tarefa de dimensionar essa contribuição, especialmente para a população negra, não foi possível nesse momento devido à falta de dados e informações sobre a condição racial dos estudantes que frequentam os cursos. Esse fator tem dificultado gestores e professores na formação de práticas diferenciadas em prol da permanência qualificada desses estudantes.

O ProUni, sem dúvida, é importante na garantia de acesso de milhões de jovens à universidade, e há diversos dados que comprovam essa afirmativa. Na RMVA, a iniciativa trouxe alento à ausência de instituições 
públicas, mas desmobilizou setores comprometidos com a implementação de universidades públicas na região.

\section{Considerações finais}

Não é nossa pretensão confrontar posições particulares com a de entrevistados e colaboradores, nem mesmo manifestar críticas sobre o Unileste/MG e as mudanças produzidas ou não por efeito da implantação do ProUni. O que pretendemos, nesta parte final do texto, é registrar o saber construído, no processo da pesquisa, sobre o problema de conhecimento investigado.

A proposta do ProUni, de garantir acesso à universidade para mais pessoas, incita algumas reflexões: o que muda no mundo acadêmico a partir da inserção de estudantes de baixa renda, negros, indígenas e oriundos de escola pública? Nesse sentido, a instituição possui o grande desafio de ser protagonista na construção de nova perspectiva educacional, que leve em conta as expectativas desse grupo em prol de sua permanência e sucesso.

Mesmo que o Movimento Negro tenha denunciado como mito, a democracia racial permanece no imaginário coletivo. A tendência tem sido diluir a raça em questões sociais mais genéricas, pensando a exclusão em um contexto de diversidade, multiculturalismo, pluralidade, homogeneizando ações, o que amortece iniciativas e práticas pensadas especificamente para determinado segmento. O que é possível depreender dessas análises é que mudanças ocasionadas pela implantação de um programa como o ProUni no contexto do Unileste/MG dependem de concepções pedagógicas, além da intencionalidade política dos professores e gestores. A forma como eles se organizam ao produzir diferentes experiências e responder, de forma favorável ou não, às inovações políticas, como o caso do ProUni, depende, sobretudo, da multiplicidade de leituras possíveis de serem realizadas por esses atores.

Nossa compreensão alinha-se à afirmação de Heringer (2006) de que, no cenário atual do debate no Brasil, o pior que pode acontecer em relação ao futuro de tais políticas é seu esvaziamento pela evasão dos estudantes beneficiados ou pela ineficiência de condições para que tenham bom desempenho na carreira. A vigilância da sociedade civil, incluídas as organizações do Movimento Negro, no que tange à concretização dessas medidas, terá papel fundamental nesse processo.

Temos também a convicção de que, no âmbito do campo e do problema pesquisado, muito precisa ainda ser compreendido e feito. As narrativas do mito da democracia racial estão ainda impregnadas no imaginário coletivo, e a crença de que vivemos em uma harmonia racial inviabiliza ações e discussões sobre a exclusão da população negra. Essa invisibilidade do problema faz-se presente nos documentos e depoimentos, em que a questão racial fica reduzida a questões genéricas, como a socioeconômica. Evidência que nos possibilita perguntar: como pensar 
práticas diferenciadas para o invisível? A democratização do acesso da população negra à universidade tem papel fundamental no exercício do direito à diferença, em um espaço de diálogo e formação de atores sociais até então invisíveis.

Essa dimensão permite pensar em outro tópico da nossa reflexão: o Movimento Negro e os deságios ante a constituição da identidade e das desigualdades raciais. Reconhecendo esse movimento como protagonista da conquista de direitos reivindicados pela população negra, surgem desafios de várias ordens: enquanto a comunidade de luta produz sujeitos coletivos, o discurso neoliberal, contaminado pela cegueira racial, enfatiza o indivíduo. Como pensar o posicionamento político coletivo no século 21? É importante ampliar, portanto, as discussões sobre racismo e neoliberalismo, o que remete a mais um tópico desta análise: as políticas públicas para o acesso ao ensino superior, entre o real e o ideal.

Tratando-se de politicas educacionais, os textos, decretos e leis são produtos de múltiplas influências e agendas, e sua formulação envolve intenções e negociação dentro do Estado e do processo de formulação da política (Mainardes, 2006). É válido, portanto, questionar que influências e agendas são reconhecidas como legítimas e que vozes são ouvidas num determinado processo. Cabe, então, a pergunta: em que medida o ProUni atende à demanda em prol da democratização do acesso ao ensino superior público de qualidade?

Assim, materializamos nossa contribuição à discussão proposta para este número da Revista, contemplando, de forma dialogada, teoria e prática, conhecimento e ação, no contexto de uma pesquisa em instituição e espaço temporal concretos, na perspectiva do grupo de professores e gestores que colaboraram com nosso estudo.

\section{Referências bibliográficas}

BENEDITO JUNIOR, Fernando. Vale do Aço 2000: um século de história. Ipatinga: Diário do Aço Empresa Jornalística Revisão, 2000.

BERNARDINO, Joaze. Ações afirmativas: respostas às questões mais frequentes. O Público e o Privado, São Paulo, n. 3, p. 88-98, jan./jun. 2004. Disponível em < http://www.sumarios.org/sites/default/files/ pdfs/59306_6843.PDF>.

BOGDAN, Roberto; BIKLEN, Sari. Investigação qualitativa em educação: uma introdução à teoria e aos métodos. Portugal: Porto, 1994.

BRASIL. Constituição da República Federativa do Brasil. Brasília: DF, Senado, 1988. Disponível em: < http://www.planalto.gov.br/ccivil_03/ constituicao/constitui\%C3\%A7ao.htm>. 
BRASIL. Lei no 9.394 de 20 de dezembro de 1996. Estabelece as diretrizes e bases da educação nacional. Diário Oficial da União, Brasília, 21 dez. 1996. Disponível em: <http://www6.senado.gov.br/ legislacao/ListaTextoIntegral.action?id $=75723>$.

BRASIL. Lei no 10.172, de 9 de janeiro de 2001. Aprova o Plano Nacional de Educação e dá outras providências. Diário Oficial da União, Brasília, 10 jan. 2001. Disponível em <http://www.planalto.gov.br/ ccivil_03/leis/leis_2001/110172.htm>. Acesso em: 17 nov. 2007.

BRASIL. Lei $n^{\circ}$ 10.639, de 9 de janeiro de 2003. Altera a Lei $n^{\circ} 9.394$, de 20 de dezembro de 1996, que estabelece as Diretrizes e Bases da Educação Nacional, para incluir no currículo oficial da Rede de Ensino a obrigatoriedade da temática "História e Cultura Afro-Brasileira". Diário Oficial da União, Brasília, 15 jan. 2003. Disponível em: < http://www. planalto.gov.br/ccivil_03/leis/2003/110.639.htm>.

BRASIL. Lei $\mathrm{n}^{\circ}$ 11.096, de 13 de janeiro de 2005. Institui o Programa Universidade para Todos (ProUni), regula a atuação de entidades beneficentes de assistência social no ensino superior, altera a Lei $\mathrm{n}^{\circ}$ 10.981, de 9 de julho de 2004. Diário Oficial da União, Brasília, 13 jan. 2005. Disponível em: < http://www.planalto.gov.br/ccivil_03/_Ato20042006/2005/Lei/L11096.htm>. Acesso em: 7 jul. 2007.

BRASIL. Medida Provisória no 213, de 10 de setembro de 2004. Institui o Programa Universidade para Todos - ProUni, regula a atuação de entidades beneficentes de assistência social no ensino superior. Diário Oficial da União, Brasília, 13 set. 2004; retificado no Diário Oficial da União, 27 set. 2004 Disponível em: < http://www.planalto.gov.br/ ccivil_03/_Ato2004-2006/2004/Mpv/213.htm>. Acesso em: 7 jul. 2007.

BRASIL. Ministério da Educação (MEC). Portaria nº 569, de 23 de fevereiro de 2006. Regulamenta o art. 11 da Lei $\mathrm{n}^{\circ} 11.180$, de 23 de setembro de 2005. 2006. Disponível em: <http:// siteprouni.mec.gov.br/index.php?option $=$ com_docman\&task $=$ doc details\&gid $=91 \&$ Itemid $=>$.

Projeto de Lei no 3.582, de 28 de março de 2004. Dispõe sobre a instituição do Programa Universidade para Todos (ProUni). Diário Oficial da União, Brasília, 29 março 2004. Disponível em: <http://www.camara.gov.br/proposicoesWeb/fichadetramitacao?idPropo sicao $=253965>$. Acesso em: 3 jul. 2007.

BRASIL. Presidência da República. Mensagem nº 9, de 9 de janeiro de 2001. [...] vetar parcialmente o Projeto de Lei $n^{\circ} 42$, de 2000 ( $\mathrm{n}^{\circ}$ 4.155/98 na Câmara dos Deputados), que "Aprova o Plano Nacional de Educação e dá outras providências". 2001. Disponível em: <http:// 
www.planalto.gov.br/ccivil_03/leis/Mensagem_Veto/2001/Mv0009-01. htm $>$.

BRASIL. Decreto de 20 de outubro de 2003. Institui Grupo de Trabalho Interministerial encarregado de analisar a situação atual e apresentar plano de ação visando a reestruturação, desenvolvimento e democratização das Instituições Federais de Ensino Superior - IFES. Diário Oficial da União, Brasília, 21 out. 2003. Disponível em: <http://www. sintunesp.org.br/refuniv/GT-Interministerial\%20-\%20Estudo.htm>.

BRASIL. Presidência da República. Grupo de Trabalho Interministerial (GTI). Bases para o enfrentamento da crise emergencial das universidades brasileiras e roteiro para a reforma da universidade brasileira. Brasília, 2003. Disponível em: < http://www.anped.org.br/ reformauniversitaria3.pdf $>$.

CARVALHO, Cristina. O ProUni no governo Lula e o jogo político em torno do acesso ao ensino superior. Educação \& Sociedade, Campinas, v. 27, n. 96, p. 979-1000, out. 2006.

CASTANHO, Maria. Universidade à noite: fim ou começo de jornada? Campinas: Papirus, 1989.

CATANI, Afrânio; HEY, Ana; GIGLIOLI, Renato. Democratização do acesso às instituições de ensino superior? Educar, Curitiba, n. 28, p. 125-140, 2006.

CONSTANTINO, Luciana. Universidades particulares pedem alteração em reserva de vagas. Folha de São Paulo, São Paulo, 12 ago. 2004, Educação. Disponível em: <www.folha.uol.com.br/folha/educacao/ ult305u15930.shtml>. Acesso em: 16 jul. 2007.

COSTA, Fabiana. Políticas públicas de educação superior Programa Universidade para Todos: um olhar dos alunos beneficiários da PUC-SP. 2008. Dissertação (Mestrado em Educação) - Pontifícia Universidade Católica (PUC), São Paulo, 2008. Disponível em: < http:// www.dominiopublico.gov.br/pesquisa/DetalheObraForm.do?select_ action $=\&$ co_obra $=110013>$.

ESCOTT, Clarice. Desigualdades raciais e ensino superior no Brasil. In: NUNES, Margarete (Org.). Diversidade e políticas afirmativas: diálogos e intercursos. Novo Hamburgo: Feevale, 2005.

FACEIRA, Lobelia. Programa Universidade para Todos: política de inclusão acadêmica e social? 2006. Disponível em <www. castelobranco.br/pesquisa/vol7/pdf/2006.pdf>. Acesso em: 15 jul. 2008. 
FERNANDES, Maria Cristina. Concepções de qualidade de ensino na perspectiva docente em um Centro Universitário privado e noturno. 2002. Tese (Doutorado em Educação Escolar) Universidade Estadual Paulista Julio de Mesquita Filho,

Araraquara, 2002.

GUIMARÃES, Antonio. Apresentação. In: GUIMARÃES, Antonio; HUNTLEY, Lynn (Orgs.). Tirando a máscara: ensaios sobre o racismo no Brasil. São Paulo: Paz e Terra, 2000.

HERINGER, Rosana. Análise das principais políticas de inclusão de estudantes negros no ensino superior no Brasil no período 20032006. Recife: Universidade Federal de Pernambuco, 2007. Disponível em < http://www.subsociologia.com.br/com>. Acesso em: $1^{\circ} \mathrm{abr}$. 2008.

. Políticas de promoção da igualdade racial no Brasil: um balanço no período 2001-2004. In: FERES JUNIOR, João; JONINSEIN, Jonas. Ação afirmativa e universidade: experiências nacionais comparadas. Brasília: UnB, 2006.

INSTITUTO BRASILEIRO DE GEOGRAFIA E ESTATÍSTICA (IBGE). Censo demográfico 2010. Disponível em < http://www.ibge.gov.br>. Acesso em: 4 abr. 2011.

LEE, Valerie E. A necessidade dos dados longitudinais na identificação do efeito-escola. Revista Brasileira de Estudos Pedagógicos, Brasília, v. 91, n. 229, p. 471-480, set./dez. 2010.

LUDKE, Menga; ANDRÉ, Marli. Pesquisa em educação: abordagens qualitativas. São Paulo: EPU, 1986.

MAINARDES, Jefferson. A abordagem do ciclo de políticas: uma contribuição para a análise de políticas educacionais. Educação \& Sociedade, Campinas, v. 27, n. 94, p. 47-69, jan./abr. 2006.

MANCEBO, Deise. Reforma universitária: reflexões sobre a privatização e a mercantilização do conhecimento. Educação \& Sociedade,

Campinas, v. 25, n. 88, p. 845-866, out. 2004. Disponível em: < http:// www.cedes.unicamp.br/revista/rev/rev88.htm>.

MARCHA ZUMBI CONTRA O RACISMO, PELA CIDADANIA E A VIDA. Por uma política nacional de combate ao racismo e à desigualdade racial. Brasília: Cultura Gráfica e Ed., 1996.

MARINHO, Luiz. Opinião. Folha de São Paulo, São Paulo, 28 fev. 2005, Opinião, p. 3. 
MINAS GERAIS. Secretaria do Estado de Desenvolvimento Regional e Política Urbana. Site oficial. 2008. Disponível em: <www.urbano. mg.gov.br/lc90.pdf>. Acesso em: 23 jan. 2009.

MUNANGA, Kabengele; GOMES, Nilma. O negro no Brasil de hoje. São Paulo: Global, 2006.

NASCIMENTO, Abdias. Documento no 7: Quilombismo: um conceito científico emergente do processo histórico-cultural das massas afrobrasileiras. In: NASCIMENTO, Abdias. Quilombismo: documentos de uma militância Pan Africana. Petrópolis: Vozes. 1980. p. 245-281.

NASCIMENTO, Abdias; NASCIMENTO, Elisa. Reflexões sobre o Movimento Negro no Brasil. In: GUIMARÃES, Antonio; HUNTLEY, Lynn (Orgs.). Tirando a máscara: ensaios sobre o racismo no Brasil. São Paulo: Paz e Terra, 2000.

NASCIMENTO, Alexandre. Racismo e antirracismo e políticas de ação afirmativa no Brasil. Revista Lugar Comum, Rio de Janeiro, n. 1920, 2007. Disponível em: <http://conferencias.iscte.pt/viewpaper. php?id $=219 \& \mathrm{cf}=3>$.

OLIVEIRA, Eliane de. Mulher negra professora universitária: trajetória, conflitos e identidade. Brasília: Líber Livro, 2006.

OLIVEIRA, Iolanda; SILVA, Petronilha. Identidade negra: pesquisas sobre o negro e a educação no Brasil. In: NEGRO e educação. Rio de Janeiro: Ação Educativa, 2004.

OTRANTO, Célia. A reforma da educação superior do governo Lula da Silva: da inspiração à implantação. In: REUNIÃO ANUAL DA ANPEd, 29., Caxambu, 2006. Anais da 29a... Caxambu: ANPEd, 2006. CD-ROM.

QUEIROZ, Delcele (Org.). O negro na universidade. Salvador: Novos Toques, 2002.

RODRIGUES, João Jorge. Direito e ação afirmativa: políticas de ação afirmativa para afro-brasileiros. 2005. Dissertação (Mestrado em Direito) - Universidade de Brasília (UnB), Brasília, 2005.

ROSEMBERG, Fúlvia. Ação afirmativa no ensino superior brasileiro: pontos para reflexão. Programa de ações afirmativas [blog], set. 2006. Disponível em: <www.acoesafirmativas.ufscar.br>. Acesso em: jul. 2007.

SARMENTO, Daniel. O negro e a igualdade no direito constitucional brasileiro: discriminação de facto, teoria do impacto desproporcional e ações afirmativas. In: FERES JUNIOR, João; ZONINZEN, Jonas (Orgs.). 
Ação afirmativa no ensino superior brasileiro universitário. Belo Horizonte: UFMG, 2008.

SAVIANI, Demerval. O plano de desenvolvimento da educação: análise do projeto do MEC. Educação \& Sociedade, Campinas, v. 28, n. 100, p. 1231-1255, out. 2007. Disponível em: < http://www.scielo.br/pdf/es/ v28n100/a2728100.pdf>.

SGUISSARDI, Valdemar. Reforma universitária no Brasil - 1995-2006: precária trajetória e incerto futuro. Educação \& Sociedade, Campinas, v. 27, n. 96, p. 1021-1056, out. 2006. Disponível em: < http://www. scielo.br/pdf/es/v27n96/a18v2796.pdf>.

SGUISSARDI, Valdemar; SILVA JUNIOR, José. A nova lei da educação superior: fortalecimento do setor público e regulação do privado/ mercantil ou continuidade da privatização do público? Revista Brasileira de Educação, Rio de Janeiro, n. 29, p. 5-27, maio-ago. 2005. Disponível em: <http://www.scielo.br/pdf/rbedu/n29/n29a02.pdf>.

SILVA, Sonaly. Capoeira: movimento e malícia em jogos de poder e resistência. 2007. Dissertação (Mestrado em Psicologia) - Pontifícia Universidade Católica (PUC-MG), Belo Horizonte, 2007. Disponível em: $<$ http://www.pucminas.br/documentos/dissertacoes_sonaly_silva.pdf>.

SILVÉRIO, Valter. Negros em movimento: a construção da autonomia pela afirmação de direitos. In: BERNARDINO, Joaze; GALDINO, Daniela (Orgs.). Levando a raça a sério: ação afirmativa e universidade. Rio de Janeiro: DP\&A, 2004.

SOUZA, Josias. Medida Provisória do ProUni cria "promamata". Folha de São Paulo, São Paulo, 26 set. 2004, Brasil, p. A14.

STAKE, Robert. Investigación com estúdio de casos. Madrid: Morata, 1999.

TELLES, Edward. Racismo à brasileira: uma nova perspectiva sociológica. Rio de Janeiro: Relume Dumará, Fundação Ford, 2003. Disponível em: < http://www.scielo.br/pdf/ha/v10n21/20631.pdf>.

TRIVIÑOS, Augusto. Bases teórico-metodológicas da pesquisa qualitativa em ciências sociais. Porto Alegre: UniRitter, 2001. 
Edna Imaculada Inácio de Oliveira, mestre em Educação pela Universidade do Vale do Rio dos Sinos (Unisinos), é professora no Centro Universitário do Leste de Minas Gerais (Unileste-MG).

eimaculada@gmail.com

Rosane Maria Kreusburg Molina, doutora em Ciências da Educação pela Universidade de Barcelona, é professora e pesquisadora do Programa de Pós-Graduação em Educação da Universidade do Vale do Rio dos Sinos (Unisinos).

rmolina@unisinos.br

Recebido em 19 de abril de 2011.

Aprovado em 18 de abril de 2012. 